Etnográfica

Revista do Centro em Rede de Investigação em

Antropologia

vol. 21 (3) | 2017

Vol. 21 (3)

\title{
Osikirip: "especiais" karitiana e a familiarização com o não indígena
}

Osikirip: Karitiana "special ones" and familiarization of the non-Indigenous

\author{
Íris Morais Araújo
}

\section{(2) OpenEdition \\ Journals}

\section{Edição electrónica}

URL: https://journals.openedition.org/etnografica/5095

DOI: 10.4000/etnografica.5095

ISSN: 2182-2891

\section{Editora}

Centro em Rede de Investigação em Antropologia

\section{Edição impressa}

Data de publição: 1 outubro 2017

Paginação: 649-661

ISSN: 0873-6561

\section{Refêrencia eletrónica}

Íris Morais Araújo, «Osikirip: "especiais" karitiana e a familiarização com o não indígena», Etnográfica [Online], vol. 21 (3) | 2017, posto online no dia 24 março 2018, consultado o 10 fevereiro 2022. URL: http://journals.openedition.org/etnografica/5095 ; DOl: https://doi.org/10.4000/etnografica.5095

\section{(c) (i) (9)}

Etnográfica is licensed under a Creative Commons Attribution-NonCommercial 4.0 International License. 


\section{Osikirip: "especiais" karitiana e a familiarização com o não indígena}

\section{Íris Morais Araújo}

O objetivo deste artigo é examinar as afecções - os efeitos nos corpos em relação - mobilizadas pelos karitiana para compreenderem seus parentes "especiais" (osikirip). A formulação do grupo justifica a existência dos últimos pelo enfraquecimento de seus corpos, em resultado da adesão à comida não indígena. O consumo cotidiano desses alimentos (arroz, feijão, macarrão, charque, carne congelada, óleo, sal, café, açúcar, biscoitos e doces) deve ser entendido como um processo de familiarização, pelo qual os karitiana propõem aos não indígenas serem por eles adotados e, assim, protegidos de sua força predadora. $\mathrm{O}$ nexo com os não indígenas, por outro lado, permite que o grupo pleiteie tratamentos médicos e benefícios sociais específicos aos "especiais", mesmo que as explicações para sua existência sejam discrepantes das oficiais.

PALAVRAS-CHAVE: karitiana, osikirip ("especiais"), corpo, familiarização, políticas sociais, afecção.

Osikirip: Karitiana "special ones" and familiarization of the non-Indigenous - The article focuses on the affections - the effects on bodies put in relation - that are mobilized by the Karitiana to understand their "special" relatives (osikirip). The group's formulation implies that the latter come to exist because of Karitiana's bodies weakening due to the ingestion of non-Indigenous food. The regular consumption of such items (rice, beans, pasta, dried meat, frozen meat, oil, salt, coffee, sugar, biscuits and sweets) should be understood as a familiarization process by which the Karitiana propose to adopt the non-indigenous and, as a consequence, to protect them from their predatory power. This connection with the non-Indigenous, on the other hand, allows for Karitiana's demand of medical care and social benefits for their "special ones", even when their existence is explained differently by the Karitiana and the non-Indigenous.

KEYWORDS: Karitiana, osikirip (“specials”), body, familiarization, social policies, affection.

ARAÚJO, Íris Morais (imaraujo688@gmail.com) - Instituto de Saúde e Sociedade, Unifesp, Brasil. 
OS KARITIANA - POPULAÇÃO DE 346 PESSOAS (EM MAIO DE 2014; Araújo 2014: 165) falante da língua de mesmo nome (da família linguística tupi-arikém), que vive em cinco aldeias e nas cidades de Porto Velho e Cacoal (estado de Rondônia, na Amazônia brasileira) - chamam determinadas pessoas de seu grupo pelo termo osikirip, traduzido para o português como "especial". O termo na língua karitiana é formado pelas palavras $o$, cabeça, e sikirip, doido. O termo "especial", em português, já foi empregado no Brasil como categoria de nominação oficial, que, atualmente, privilegia - não sem evitar ambiguidades e disputas de sentido (Lopes 2014: 16-50) - as palavras "deficiente" e "deficiência".2 Os karitiana justificam a existência de pessoas "especiais" em função de relações que produzem "efeitos definhantes" (Macedo 2013: 185) em seus corpos. ${ }^{3}$ Proponho no presente artigo explorar uma dessas formulações karitiana: a que afirma a existência de "especiais" em função do enfraquecimento geral de seus corpos, resultado da adoção pelo grupo da dieta não indígena. ${ }^{4}$

A equivalência entre osikirip e "especial" parece ser uma "oportunidade de criar relações" (Zea 2008: 75) com os não indígenas. Os “especiais” karitiana beneficiam das políticas de proteção social voltadas à população deficiente brasileira. São detentores do "benefício de prestação continuada", que assegura ao deficiente de baixa renda o pagamento mensal de um salário mínimo. ${ }^{5}$ Para

I Este artigo é resultado de uma pesquisa de doutorado (Araújo 2014) no âmbito do PPGAS da Universidade de São Paulo (USP), orientada por Marta Amoroso e financiada pela Capes. Agradeço a Marco Antonio Gonçalves, Laura Pérez Gil, Felipe Vander Velden e Sylvia Caiuby Novaes, que arguiram a tese em março de 2015.

2 "Especial" continua, todavia, a fazer parte do linguajar cotidiano no país. O questionamento da legitimidade desse termo ocorreu por meio do embate político das organizações de pessoas deficientes, que se iniciou no começo dos anos 1980 e que buscava, sobretudo, a afirmação de direitos. "A crítica do movimento a esses eufemismos se deve ao fato de o adjetivo 'especial' criar uma categoria que não combina com a luta por inclusão e por equiparação de direitos” (Lanna Jr. 2010: 17).

3 Macedo recupera os apontamentos de Deleuze em sua leitura de Espinosa, que toma o corpo segundo o estabelecimento de boas ou más relações, que aumentam ou diminuem sua capacidade de ação: "De acordo com Espinosa, um corpo corresponde a uma relação composta ou complexa de movimentos e repousos que se mantém através das mudanças que afetam suas partes. O efeito de um corpo sobre outro constitui o que o autor chama de afecção (affectio), que pode destruir a configuração relacional constitutiva do corpo afetado ou parte das relações que o compõem. Ou, ao contrário, pode potencializar essas relações, maximizando no sujeito sua capacidade agentiva, o que constitui um bom encontro" (Macedo 2013: 185).

4 Esse mesmo mote karitiana foi objeto de análise de Felipe Vander Velden (2008), tendo em vista destacar como a introdução do sal e do óleo produziu efeitos no sistema de domínios gustativos karitiana.

5 Instituído pela Constituição Federal de 1988 e operacionalizado pelo Instituto Nacional do Seguro Social - INSS, o "benefício de prestação continuada” é definido na Lei Orgânica da Assistência Social e alterações subsequentes como "a garantia de um salário-mínimo mensal à pessoa com deficiência e ao idoso com 65 (sessenta e cinco) anos ou mais que comprovem não possuir meios de prover a própria manutenção nem de tê-la provida por sua família. [...] Para efeito de concessão do benefício [continua] 
usufruírem desse benefício, os karitiana demandam, por intermédio da Secretaria Especial de Saúde Indígena - Sesai, consultas na rede pública de Porto Velho, nas quais os médicos, por meio de exames específicos, atestam que tais pacientes são deficientes. Ao serem diagnosticados, os karitiana se transformam em pacientes de terapêuticas médicas, particularmente de medicamentos psicotrópicos. ${ }^{6}$

A gravidez é o período crítico que determina a condição dos "especiais". Sobre a mulher recai a responsabilidade pela existência do filho "especial", e ela será a referência principal nos cuidados específicos que essas crianças requerem. A remissão ao fato de ter ocorrido algo de errado nesse período é causa de enorme sofrimento, tanto para essas mulheres quanto para seus filhos. As mães sempre ressaltaram, porém, a ignorância do fato de os terem gerado assim até seu nascimento: no pré-natal, mesmo tendo realizado exames diversos, o médico não teria detectado nada de diferente com a gestação. Posteriormente, elas mesmas (ou, raras vezes, o médico), notando a dificuldade de a criança se alimentar ou aprender a andar e a falar, passaram a percebê-la como "especial". A metamorfose corporal implica uma nova posição social, como já enunciava Viveiros de Castro (1979: 40-41) em sua pesquisa sobre a fabricação do corpo yawalapiti.

A condição de "especial" é visível nos corpos, sujeitos ao escrutínio de todos. Os karitiana notam suas vicissitudes: o olho torto, a perna fina, a cabeça pequena, a magreza, o coração fraco, a garganta aberta, a ausência de intestino, os rins débeis. Há algo de repugnante nos "especiais" - e que não coincide com o que se chama de deficiência física, pois não necessariamente limita o funcionamento físico-motor daquele que é assim considerado -, o que permite aos karitiana chamá-los (ofendendo-os) de sara: feios, errados, ruins.

de prestação continuada, considera-se pessoa com deficiência aquela que tem impedimento de longo prazo de natureza física, mental, intelectual ou sensorial, o qual, em interação com uma ou mais barreiras, pode obstruir sua participação plena e efetiva na sociedade em igualdade de condições com as demais pessoas. [...] Considera-se incapaz de prover a manutenção da pessoa com deficiência ou idosa a família cuja renda mensal per capita seja inferior a 1/4 (um quarto) do salário-mínimo" (art. $20 .^{\circ}$ da Lei N. ${ }^{\circ} 8742$, de 7 de dezembro de 1993, alterada pela Lei N. ${ }^{\circ} 12.435$, de 2011 , e pela Lei N. ${ }^{\circ}$ 13.146, de 2015, disponível em < http://www.planalto.gov.br/ccivil_03/leis/L8742compilado.htm > (última consulta em outubro de 2017).

6 Dada a precariedade geral do sistema de saúde pública no Brasil, que atinge as populações indígenas de forma particularmente violenta, pode-se afirmar que os karitiana possuem acesso aos equipamentos de saúde públicos brasileiros. Nos períodos em que estive com os karitiana, todos posteriores à criação da Sesai, foi uma constante observar estadias de agentes de controle biológico, dentista, enfermeiro e técnicos em enfermagem. Vi o técnico em enfermagem visitando casas, aferindo a pressão dos karitiana, acompanhando o peso de crianças e idosos. Também presenciei equipes maiores, por exemplo, de agentes de controle biológico aplicando inseticida, ou de técnicos e enfermeiros em campanha para verificação de diabetes e aplicando vacinas. Além dos cuidados promovidos em prol da saúde no cotidiano aldeão, os enfermeiros possuem papel central para o acesso dos karitiana às consultas médicas que ocorrem na rede pública de Porto Velho. 
O termo karitiana condensa qualificação estética, ética e moral e, como defende Overing (1991: 24) em sua reflexão sobre como é concebido o social entre os cubeo e os piaroa, essa caracterização demarca atributos negativos das pessoas assim chamadas.

Em adição ao corpo asqueroso, os karitiana enumeram as dificuldades em falar, comer e aprender, bem como a excessiva raiva de seus próprios parentes, como aspectos que particularizam os "especiais". Esses últimos se caracterizam por dificuldades nas habilidades que, segundo Gow (1997), são fulcrais para determinar a humanidade entre populações que se definem por meio das relações de parentesco, uma vez que tais embaraços impedem a completa aquisição de linguagem e consciência que permitem, justamente, a percepção de tais relações. Além disso, a raiva é, para esses mesmos grupos, considerada uma forma de relação privilegiada para lidar com o mundo exterior (Castro 2002a: 163-180), mas vedada aos nexos entre iguais (Overing 1991: 24).

A despeito dessas ressalvas, os karitiana não colocam em dúvida que os “especiais" sejam parentes - ou seja, humanos (Gow 1997). Meus anfitrióes esforçam-se por construir um cotidiano, lugar da valorização da socialidade (Overing 1999), com os "especiais", mesmo que não disponham inteiramente das "maneiras ou de modos de ser que constituem um habitus" (Castro 2002b: 380). Assim, tais pessoas são extremamente cuidadas e incentivadas a participar das tarefas cotidianas - fazendo com que o neófito no convívio com os karitiana tenha dificuldade em notar quem são os "especiais" -, mesmo que nem sempre sejam capazes de fazê-las sozinhos.

Para relacionar a proliferação de "especiais" e o estabelecimento de vínculo com não indígenas, recorro ao mito de Byyjyty (Grande Chefe), neto de Botỹj, o humano primordial, que formula tal o nexo. Botỹj e Byyjyty foram os responsáveis pelo surgimento dos karitiana; o último os fez das mechas do seu cabelo cortado. Byyjyty, contudo, não pôde evitar que o encontro dos karitiana com os não indígenas fosse pautado pela tragédia, pois os primeiros não ouviram seus conselhos sobre a forma de agir com tais seres poderosos, cujas armas eram de fogo. De acordo com a narrativa karitiana (Araújo 2014: 27-29; Lúcio 1996: 25-31), Byyjyty, em suas andanças, chegou à Água Grande, a morada do traiçoeiro Ora, irmão caçula de seu avô. Lá viu os parentes de Ora, os não indígenas. Viu uma criança, que não queria sair da água. Mas Byyjyty ofereceu-lhe carne: ela aceitou e ficou mansa. Seduzidos pela comida, muitos outros não indígenas vieram para perto de Byyjyty; alimentando-os, amansou os não indígenas. À medida que ingeriam sua comida, viravam seus parentes.

De volta para perto dos karitiana, Byyjyty avisou-os de que morreria e que em alguma hora apareceria por ali um grupo diferente, cujos homens possuíam barba. Os karitiana não deveriam matá-los, pois eram muito poderosos. Porém, quando os não indígenas apareceram, os karitiana já não se lembravam das recomendações de Byyjyty e atiraram suas flechas. Um dos 
não indígenas sobreviveu e vingou seus parentes mortos com suas potentes metralhadoras.

A familiarização dos não indígenas - criaturas perigosas por excelência, pois parentes de Ora e donas das potentes armas de fogo - empreendida por Byyjyty não foi aproveitada pelos karitiana. Frente aos atos desastrados dos caçadores, que se esqueceram do pedido do chefe de jamais matar aquela gente diferente, o grupo passou a ser alvo da raiva dos barbudos.

Diante de tamanha fúria, aos karitiana restou tentar lembrar aos não indígenas a origem comum dos dois grupos - familiarizados por Byyjyty, ambos se tornam "netos de Botỹj”, o humano primordial. A música Opok a’akap ("Para o não indígena amar"), que meus anfitriões consideram seu "hino nacional", formula a possibilidade de um vínculo de familiarização pelo qual os karitiana procuram ser alimentados e protegidos, mostrando-se, assim, dispostos a se dotar das disposições características dos seus protetores (Fausto 2002: 15).

Yjxaty takyryoop

Gootak na'ak tykakiibm

Yjtiity'o tyyn naakat horo

Gootak na'ak tykakiibm

Yjhyryryp tyyn naakat horo

Gootak na'ak tykakiibm

Byyjyty ot'sop aky tyyn naakat horo

Gootak na'ak tykakiibm

Yjxaty takyryoop

Gootak na'ak tykakiibm

Botỹj ogoto tyyn naakat horo

Yjxaty ty'a tykatyyn

Gootak na'ak tykakiibm

Yjaty takyryoop

Owãowok pympasa

Gootak na'ak tykakiibm
Tenha pena de nós

Quem pisa no mato irá nos amar muito É nossa Grande Mãe também, não é mesmo?

Quem pisa no mato irá nos amar muito

Nós somos iguais também, não é mesmo?

Quem pisa no mato irá nos amar muito

É feito do cabelo de Byyjyty também, não é mesmo?

Quem pisa no mato irá nos amar muito

Tenha pena de nós

Quem pisa no mato irá nos amar muito

É neto de Botỹj também, não é mesmo?

Nós ** muito juntos

Quem pisa no mato irá nos amar muito

Tenha pena de nós

Ame-nos como um bebê

Quem pisa no mato irá nos amar muito

Tomando o processo de familiarização empreendido pelo neto do humano primordial, o grupo se define, para os não indígenas, pela mesma ascendência: ambos são netos de Botỹj, e feitos do cabelo de Byyjyty. A despeito da origem comum, a relação desenhada pelos karitiana é marcada pela assimetria. Esse segundo nexo de familiarização é definido por meio de forte linguagem afetiva: meus anfitriões são pequenos recém-nascidos, dignos de pena e amor dos homens barbudos, suas Grandes Mães (yjtiity). O sentido dessa relação, na qual os "adultos" se mobilizam para cuidarem e satisfazerem os desejos dos "bebês", parece próximo à formulação de Gow sobre o modo como os piro 
concebem tal relação: "Por que as pessoas alimentam e cuidam de bebezinhos? Elas o fazem porque eles são kwamonuru, 'bonitinhos, tristes, coitados, pobrezinhos'. Isto suscita getwamonuta, 'ver a tristeza, pena, desamparo, graciosidade de alguém" " (Gow 1997: 53).

Como recém-nascidos desamparados, os karitiana se colocam nesse vínculo, como propõe Bonilla para o modo paumari de constituir relações, "do ponto de vista da presa, do objeto da familiarização, e não do ponto de vista do predador ou do domesticador" (2005: 49). A autora considera que a população do rio Purus, ao deslocar o não indígena da posição do inimigo para a de patrão, minimiza o perigo da devoração pelo estrangeiro potencialmente predador. "A arma predatória dos paumari seria sua capacidade de submissão, submissão esta que obrigaria qualquer interlocutor em posição de dominação a apiedar-se deles e a adotá-los" (Bonilla 2005: 59).

Os karitiana, tal como os paumari, parecem solicitar dos não indígenas que não sejam tratados como inimigos, neutralizando sua fúria predadora, mas sim familiarizados, que sejam cuidados como bebês. Para usar o vocabulário proposto por Fausto (2008: 351), estamos diante de uma relação de filiação adotiva, que combina obrigatoriamente identidade e assimetria e na qual o lugar que os karitiana ocupam é o do filho-xerimbabo. Aos não indígenas cabe, como Grandes Mães, tornar-se dono-mestre, proporcionando ao grupo a sua proteção. A canção Opok a'akap, explicou-me um amigo, faz com que o estrangeiro fique calmo, e a ele seja impossível não oferecer comida aos karitiana.

É desse ângulo - o fato de o grupo procurar, como um bebê, ser alimentado pela Grande Mãe não indígena - que retomo as notícias dos primeiros encontros dos atuais seniores karitiana com os seringueiros. O depoimento que se segue, de Antônio Paulo Karitiana à historiadora Lílian Moser, é uma elaboração das tentativas dos karitiana em estabelecer relações com não indígenas. $^{7}$

O narrador nos remete ao tempo de aliciamento para a extração de copaíba, sorva, caucho e seringa. O excesso de trabalho levou a reações de fuga. Do que se conhece dessa história, por décadas, os karitiana realizaram movimentos pendulares de aproximação e distanciamento dos seringueiros (Velden 2012: 46-60). Nesses períodos de encontro, os não indígenas forneciam sal, machados, trados, facões, munições, óleo, arroz, feijão, charque, açúcar, conservas, sardinha, farinha, espoletas, pólvora. E remédio - "pílula pequenininha e grande" -, pois traziam para a floresta também a gripe.

7 A historiadora recolheu depoimentos de diversos karitiana a respeito de sua experiência com os não indígenas. A narrativa de Antônio Paulo Karitiana ora apresentada já foi considerada também por Felipe Vander Velden (2008) em sua análise sobre os efeitos da introdução do sal e demais alimentos exógenos pelos seringueiros. 
“Moraes, pai do Amoiré, viu o primeiro seringueiro no Rio Candeias. [... 'Rapaz, vamos ver os brancos que estavam trabalhando lá?', ele falou. 'Então, vamos, vamos pegar sal'. [...] Moraes chegou: 'Oi, compadre. Tudo bom?' Ele não sabia o português, falava um bocadinho. 'Rapaz, nós queremos sal. Compadre, sal!' 'Sal, vocês querem? Então, pega aî'. Um pacotão de sal. 'Está aí o sal. Leva, leva aí para o pessoal de vocês'. 'Está bom!' pegou, carregou nas costas mesmo. Levaram trinta quilômetros até chegar na aldeia. 'Rapaz, branco é bom! Ele deu sal pra gente'. 'Rapaz, vamos embora lá porque as pessoas já usaram todinho [...] Eu estou lá amanhã, estão cuidando bem', Moraes falou. 'Oi, compadre!', o seringueiro que estava ouvindo disse. E completou: ‘Opa, chegou de novo o índio’. Tinha muita mercadoria no seringueiro. 'Oi, compadre! Tudo bom, compadre? Do que vocês precisam?' 'Nós precisamos de sal, machado, trado, facão, munição'. 'Está bom, compadre! Entra aqui'. [...] 'Rapaz, dê para ele óleo. Não conhece nada. Você não conhece nada. Você conhece óleo? Arroz? Feijão? Aí tem charque. Leva'. [...] 'Isso aqui é pra vocês. Isso aqui é sal, isso é açúcar, isso é óleo, charque (jabá), tudinho. Isso aqui é espoleta, pólvora, tudinho'. [...]

O branco chegou lá. 'Oi, compadre!'; 'Oi, compadre!' 'Nós precisamos de você para trabalhar para nós, tirar copaíba, sorva também, caucho'. 'Vai trabalhar comigo, tirar copaíba, sorva, caucho e seringa'. [...] Estava trabalhando primeiro, trabalhou, trabalhou todo dia, todo dia. Tem produção muito, tinha de trabalhar muito, tinha de trabalhar tudo, todo mundo reunido. [...] Então, Moraes pensou: 'Não vamos mais morar junto com os brancos, não; senão [...] o seringueiro vai pegar a gente'.

Então, os indígenas saíram do lugar, se mandaram para outro canto. [...] Demorou, demorou, demorou muito, até cinco anos, dez anos. Então, Moraes falou: 'Não tem sal, acabou o sal' [... 'Vamos de novo lá nos brancos buscar sal, açúcar'. [...] Pegaram o caminho, caminhando de novo para lá. Chegaram de novo. Diz que estava o Figueiredo. 'Oi, compadre!'. Figueiredo tinha muita mercadoria. Então, ele disse: 'Chega, compadre!'. 'Compadre, nós queremos sal. Onde tem sal, compadre?' 'Sal tem amontoado de sal, mercadoria, todo ele, muito. Leva tudo isso pra lá'. Ele deu conserva, sardinhas e farinha, óleo, açúcar. [...]

Fomos andando, andando, até chegar na maloca. Nós chegamos. Rapaz, então, caiu de gripe, tosse, ficou doente! 'Rapaz, vamos embora daqui!' E se mandou mais uma vez para lá. Só Moraes ficou primeiro no seu lugar. Aqui, doente chegou. Aqui, pegou da gente. Saiu daqui, aqui doente, pegou da gente. Saiu. Ficou rodando, rodando, Moraes. [...] Deu remédio também. Remédio que as pessoas deram para ele. Remédio, antigamente, era pílula pequenininha e grande. Não tinha tanto assim remédio" (Antônio Paulo Karitiana, em Moser 1993: 96-100). 
A narrativa de Antônio Paulo Karitiana elabora o ciclo, vivido de modo geral pelas populações indígenas amazônicas, de aproximação ao invasor de seu território, troca de mercadorias pelo engajamento na teia extrativista e afastamento pela doença. A completa distância, contudo, nunca mais ocorreria: Moraes, o cacique que é protagonista dessa história, resolveu viver perto dos seringueiros. Das suas mãos chegariam também as pílulas para aplacar a epidemia.

Os alimentos que tiveram a primeira oportunidade de experimentar nesses encontros com os seringueiros são, já há algumas décadas, parte da vida cotidiana de meus anfitriões. Além de macaxeira cozida, carne de caça e frutas dos pomares e do mato, a alimentação dos karitiana é constituída de café (com açúcar), biscoitos e doces, arroz, feijão, macarrão e charque ou carne congelada (com sal e óleo, gordura vegetal) (Velden 2008: 25).

Não se deve subestimar o papel da Funai - "mãe do índio", segundo meus anfitriões - nessa transformação. O órgão indigenista, amparado pelo ideário tutelar que marcou sua atuação nos anos 1970 (Santilli 1991: 11), operou em prol da estabilização de nexos entre indígenas e sociedade envolvente no momento periclitante de declínio populacional dos karitiana. Os karitiana, saudosos do tempo em que a Funai era "forte", recordam-se que o indigenismo oficial lhes oferecia cestas básicas regularmente. ${ }^{8}$

Esse processo de substituição do que comem, porém, não é isento de complicações. Afinal, ingerir o alimento exógeno não apenas interliga o grupo aos não indígenas, como proporciona, obrigatoriamente, uma transformação corporal daqueles que o consomem. Na concepção karitiana, o alimento dos não indígenas os condenou a um processo de modificação corporal drástico, que os debilitou. Por isso, afirmam que, quando viviam no mato, eram grandes e fortes; hoje, são pequenos e fracos. Nos termos de Felipe Vander Velden, "no passado, fortes, altos, vigorosos, seus corpos retos, duros, ágeis, lisos e saudáveis [...] atualmente, baixos, pequenos, fracos, doentios, [...] curvados, pesados, sujos" (2008: 27-28, itálicos no original).

A complexa transformação corporal que resultou do esforço karitiana em se alimentar dos mantimentos oferecidos pelo não indígena, além de estabilizar a relação com aquele que foi concebido como Grande Mãe, também os permitiu conhecer seu ponto de vista e seu habitus (Castro 2002b: 380): "provar o alimento do outro faz enxergar, sentir, agir como o outro, em-corporar suas afecções" (Velden 2008: 33, itálicos no original).

8 Os karitiana referem-se ao relacionamento entre o grupo e o órgão indigenista utilizando-se do nome da fundação. "Antigamente, a Funai era forte!" foi uma frase que ouvi seguidamente ao longo da pesquisa. Alguns nomes de funcionários - chefes de posto, diretores regionais - são igualmente lembrados. Trabalho ainda por fazer é uma análise das narrativas dos karitiana sobre essas pessoas, como fez Vilaça (2006: 369-489) em pesquisa com os wari'. 
Comer preferencialmente arroz, feijão, macarrão e charque ou carne congelada, como aprenderam desde os encontros com os seringueiros, facultou aos meus anfitriões, desde o seu ponto de vista, adentrar no domínio não indígena. As consequências desse processo parecem inesgotáveis. Entre as muitas coisas desse novo mundo que aos karitiana se tornaram conhecidas está que os não indígenas são pais, mães e filhos de "especiais". Em seus passeios por Porto Velho, ainda hoje, ficam impressionados pela quantidade de alunos agregados pela escola específica para tais pessoas (a Associação de Pais e Amigos dos Excepcionais - APAE, instituição que atua em todo o Brasil). Os karitiana sabem, principalmente, que há médicos e remédios, além de um benefício em dinheiro para essas pessoas, o que, sob sua perspectiva, altera positivamente a vida delas.

Kelly (2009; ver também Garnelo 2003) defende a compreensão dos modos de relação das populações ameríndias com sistemas de saúde exógenos por meio das suas cosmopolíticas. É por avaliarem estar em solo estrangeiro - no caso karitiana, da Grande Mãe - que fica garantida, desde o olhar indígena, a eficácia do tratamento médico.

"O sistema de saúde participa, agora desde uma perspectiva indígena, de uma economia simbólica da alteridade que constrói relações e significados sociais [...] o status de 'estrangeiros' e 'inimigos potenciais' dos brancos tem repercussões no caráter e na eficiência do sistema de saúde que superam, de longe, as consequências derivadas das incompatibilidades no conhecimento e da prática médica entre os yanomamis e os profissionais de saúde brancos" (Kelly 2009: 277).

Ao se colocarem disponíveis aos sistemas de saúde e assistência social, os karitiana procuraram realizar o que Mauro Almeida (2003, 2013) denominou "acordo pragmático" - "diferentes sistemas do mundo podem entrar em acordo sobre certas consequências pragmáticas de seus postulados, sem que haja correspondência entre esses postulados ou sobre as visões de mundo respectivas" (Almeida 2003: 16).

Tal assertiva, por sua vez, remete a outros estudos que relacionam transformação corporal e vínculos com os não indígenas com a perspectiva de afastar argumentos oriundos das teorias de contato/aculturação. É o caso do estudo de Aparecida Vilaça (2007), que enfatiza os não indígenas como apenas um, dentre muitos "outros", com os quais as populações ameríndias se relacionam acionando a lógica xamânica - que implica percursos corporais - na construção de relações de alteridade. A autora defende que a elaboração ameríndia sobre tais vínculos específicos é uma "fisiologia do contato", uma vez que o referido nexo os leva a novas experiências corporais, como, por exemplo, relativamente ao que comem ou vestem. 
Já Oakdale (2008) analisa as narrativas biográficas de Sabino e Prepori Kayabi com o intuito de apreender suas experiências corporais em meio às primeiras interações com os não indígenas. A autora conclui que os bens manufaturados, os quais conheceram nessa ocasião, não tiveram o mesmo potencial de transformação do que o compartilhamento de comida com o não indígena e a consequente produção de uma vida diária com esse "outro".

Viegas (2012), por seu turno, põe em relevo a propensão dos tupinambá para tomar a giroba, uma bebida fermentada, semiamarga, feita de aipim. Consumida morna, desde a primeira infância, a giroba, ao mesmo tempo que os torna fortes, os diferencia da população regional, que não a aprecia. A autora sublinha que tal ingestão é central na socialidade tupinambá, uma vez que acarreta disposições corporais específicas e o reforço dos vínculos de parentesco.

Os karitiana, da mesma maneira, optam por lidar com um sistema exterior e ontologicamente distinto do seu, sabendo, de alguma maneira, que os médicos e assistentes sociais utilizam "diferentes métodos de determinar os fatos e avaliá-los” (Almeida 2003: 18). Apostam, contudo, que podem ser comensuráveis na produção de verdades. Se os médicos também aferem que alguns karitiana são "especiais", esses últimos são particularmente beneficiados, com dinheiro e remédios.

$\mathrm{O}$ acordo não anula, porém, a diversidade de pressupostos em jogo ou, nos termos de Mauro Almeida, a "verdade pragmática não elimina a ambiguidade ontológica" (2013: 12, nota 13). Os critérios que meus anfitriões utilizam para definir quem é "especial" são diferentes daqueles mobilizados pelos não indígenas - particularmente pelos médicos que os diagnosticam. Eduardo Viveiros de Castro denominou com o termo "equivocação" esse "tipo de disjunção comunicativa onde os interlocutores não estão falando sobre a mesma coisa" (2004: 9). Para o autor, essa "alteridade referencial entre conceitos homonímicos" (Castro 2004: 5) fundamenta a relação com a exterioridade, onde há necessariamente duas linguagens em jogo. Por isso, a equivocação não pode ser compreendida como um simples conjunto de erros ou enganos, é sim uma consequência do fato de que há pelo menos duas lógicas distintas em operação por trás da mesma noção. "Um erro ou engano só pode ser determinado como tal desde dentro de um dado jogo de linguagem, enquanto uma equivocação é o que se desenrola no intervalo entre diferentes jogos de linguagem" (Castro 2004: 11).

A operação de equivocação não deve ser tomada, portanto, como empecilho para os karitiana participarem dos sistemas de saúde e assistência não indígenas; ao contrário, é em resultado de proporem esse acordo, de estarem dispostos às terapêuticas caudatárias da medicina e aos benefícios da assistência social que tal comunicação disjuntiva se atualiza. 
Assim, é por haver no mínimo duas lógicas em cena na definição dos “especiais” - a do grupo e a do não indígena - que alguns karitiana assim chamados acabam não sendo considerados da mesma maneira quando pleiteiam tratamento médico e o "benefício de prestação continuada". Enquanto meus anfitriões notam - dentre outras explicações - a diminuição da capacidade de suas mulheres em gerar filhos por conta do estabelecimento de relações com não indígenas, os profissionais de saúde explicam o fenômeno tomando a genética como referência primordial.

É notável que a aproximação dos karitiana com o indigenismo oficial como, de resto, das populações indígenas consideradas de "contato recente" que vivem em Rondônia - tenha reverberado muito rapidamente na chegada de equipes médicas que os tomaram como objeto de estudo. Os grupos indígenas desse estado estão, desde os anos de 1970, entre os mais bem estudados do país pela medicina.

Com efeito, os próprios karitiana reconhecem que "quase acabaram". O declínio populacional, consequência da intensificação de relações com os não indígenas - os karitiana receberam as primeiras menções oficiais, no âmbito da Comissão Rondon, em 1907, quando foram localizados no rio Jamari, e dois anos depois, no rio Jaci-Paraná, em conflito com os seringueiros que ocupavam a região (Velden 2012: 48) -, foi violento de tal forma que Darcy Ribeiro (1996: 263), em 1957, os considerou extintos. O desaparecimento não ocorreu em função das medidas concretas tomadas pelos karitiana. Antônio Moraes - o mesmo que, segundo o depoimento de Antônio Paulo Karitiana, estabeleceu-se próximo aos seringueiros em busca de sal e outras mercadorias - desposou muitas mulheres, algumas delas interditas pelas regras de casamento. Ademais, dois grupos locais distintos, que se mantiveram relativamente afastados por algumas décadas, reencontraram-se e estabeleceram alianças.

As estratégias reverteram a depressão populacional, ao passo que geraram consequências imprevistas. Ao visitar os karitiana, o geneticista Gilberto Souza Aguiar (1991) verificou que todos os que tinham menos de 16 anos descendiam de Antônio Moraes. Segundo o mesmo pesquisador, o coeficiente de consanguinidade médio do grupo era de 0,142 (esse número entre irmãos é 0,5; entre meios-irmãos, 0,25; e entre primos de primeiro grau, 0,125). $\mathrm{Na}$ genealogia dos karitiana, os pesquisadores das hard sciences notaram, portanto, uma estrutura genética específica.

As conversas informais que mantive com os profissionais de saúde que atendem os karitiana me causaram forte impressão de que essa história toda - o quase desaparecimento, a recuperação demográfica sui generis, a genealogia intrincada, o código genético específico - é por eles conhecida. Mesmo que a ignorassem, o ponto é que tomam os pressupostos dessa ciência para compreender os "especiais" karitiana. Um grupo muito pequeno, que quase se 
extinguiu, e que se casa entre si: tal é a explicação desses profissionais para a existência de "especiais".

Mas meus anfitriões karitiana têm suas próprias teorias para explicar a existência dessas pessoas, e que não passam pelo fato de o grupo quase ter acabado, tampouco por conta de suas regras de casamento. São, antes de tudo, as mulheres e os seus corpos enfraquecidos que estão em sua mira.

\section{BIBLIOGRAFIA}

AGUIAR, Gilberto Souza, 1991, "Poligamia, endogamia e parentesco genético”, Ciência Hoje, 13 (76): 14-15.

ALMEIDA, Mauro, 2003, "Relativismo antropológico e objetividade etnográfica", Campos: Revista de Antropologia Social, 3: 9-30.

ALMEIDA, Mauro, 2013, "Caipora e outros conflitos ontológicos”, R@U: Revista de Antropologia da UFSCar, 5 (1): 7-28.

ARAÚJO, Íris Morais, 2014, Osikirip: os "Especiais" Karitiana e a Noção de Pessoa Ameríndia. São Paulo, FFLCH-USP, tese de doutorado em Antropologia Social.

BONILLA, Oiara, 2005, “O bom patrão e o inimigo voraz: predação e comércio na cosmologia paumari”, Mana: Estudos de Antropologia Social, 11 (1): 41-66.

CASTRO, Eduardo Viveiros de, 1979, "A fabricação do corpo na sociedade xinguana”, Boletim do Museu Nacional, 32: 40-49.

CASTRO, Eduardo Viveiros de, 2002a, "O problema da afinidade na Amazônia”, em E. V. Castro, A Inconstância da Alma Selvagem e Outros Ensaios de Antropologia. São Paulo, Cosac Naify, 87-180.

CASTRO, Eduardo Viveiros de, 2002b, "Perspectivismo e multinaturalismo na América indígena”, em E.V. Castro, A Inconstância da Alma Selvagem e Outros Ensaios de Antropologia. São Paulo, Cosac Naify, 345-399.

CASTRO, Eduardo Viveiros de, 2004, "Perspectival anthropology and the method of controlled equivocation", Tipití: Journal of the Society for the Anthropology of Lowland South America, 2 (1): 3-22.

FAUSTO, Carlos, 2002, "Banquete de gente: comensalidade e canibalismo na Amazônia”, Mana: Estudos de Antropologia Social, 8 (2): 7-44.

FAUSTO, Carlos, 2008, "Donos demais: maestria e domínio na Amazônia”, Mana: Estudos de Antropologia Social, 14 (2): 329-366.

GARnelO, Luiza, 2003, Poder, Hierarquia e Reciprocidade: Saúde e Harmonia entre os Baniwa do Alto Rio Negro. Rio de Janeiro, Editora Fiocruz.

GOW, Peter, 1997, "O parentesco como consciência humana: o caso dos piro", Mana: Estudos de Antropologia Social, 3 (2): 39-65.

KELLY, José Antonio, 2009, “Os encontros de saberes: equívocos entre índios e Estado em torno das políticas de saúde indígena na Venezuela", Ilha: Revista de Antropologia, 11 (2): 265-302. 
LANNA Jr., Mário Cléber Martins (org.), 2010, História do Movimento Político das Pessoas com Deficiência no Brasil. Brasília, Secretaria de Direitos Humanos/Secretaria Nacional de Promoção dos Direitos da Pessoa com Deficiência.

LOPES, Pedro, 2014, Negociando Deficiências: Sobre Identidades, Subjetividades e Corporalidades entre Pessoas com Deficiência Intelectual. São Paulo, FFLCH-USP, dissertação de mestrado em Antropologia Social.

LÚCIO, Carlos Frederico, 1996, Sobre Algumas Formas de Classificação Social: Etnografia sobre os Karitiana de Rondônia (Tupi-Arikém). Campinas, IFCH-Unicamp, dissertação de mestrado em Antropologia Social.

MACEDO, Valéria, 2013, "De encontros nos corpos guarani”, Ilha: Revista de Antropologia, 15 (2): 181-210.

MOSER, Lílian, 1993, Os Karitiana e a Colonização Recente em Rondônia. Porto Velho, UNIR, trabalho de conclusão de curso em História.

OAKDALE, Suzanne, 2008, “The commensality of 'contact', 'pacification', and inter-ethnic relations in the Amazon: Kayabi autobiographical perspectives", Journal of the Royal Anthropological Institute (n.s.), 14: 791-807.

OVERING, Joanna, 1991, "A estética da produção: o senso de comunidade entre os cubeo e os piaroa", Revista de Antropologia, 34: 7-33.

OVERING, Joanna, 1999, "Elogio do cotidiano: a confiança e a arte da vida social em uma comunidade amazônica”, Mana: Estudos de Antropologia Social, 5 (1): 81-107.

RIBEIRO, Darcy, 1996, Os Índios e a Civilização: A Integração das Populações Indígenas no Brasil Moderno. São Paulo, Companhia das Letras.

SANTILLI, Márcio, 1991, "Os direitos indígenas na Constituição brasileira”, em AAVV, Povos Indígenas no Brasil: 1987/88/89/90. São Paulo, Centro Ecuménico de Documentação e Informação, 1 1-14.

VELDEN, Felipe Ferreira Vander, 2008, “O gosto dos outros: o sal e a transformação dos corpos entre os Karitiana no sudeste da Amazônia”, Temáticas: Revista dos Pós-Graduandos em Ciências Sociais IFCH-Unicamp, 31-32: 13-49.

VELDEN, Felipe Ferreira Vander, 2012, Inquietas Companhias: Sobre os Animais de Criação entre os Karitiana. São Paulo, Alameda.

VIEGAS, Susana de Matos, 2012, "Pleasures that differenciate: transformational bodies among the Tupinambá of Olivença (Atlantic Coast, Brazil)", Journal of the Royal Anthropological Institute, 18 (3): 536-553.

VILAÇA, Aparecida, 2006, Quem Somos Nós: Os Wari’ Encontram os Brancos. Rio de Janeiro, Editora da UFRJ.

VILAÇA, Aparecida, 2007, "Cultural change as body metamorphosis", em Carlos Fausto e Michael Heckenberger (orgs.), Time and Memory in Indigenous Amazonia: Anthropological Perspectives. Gainesville, University Press of Florida, 169-193.

ZEA, Evelyn Schuler, 2008, "Genitivo da tradução", Boletim do Museu Paraense Emílio Goeldi, 3 (1): $65-77$. 